\title{
EL OBELISCO DE RAMSÉS II EN FRANCIA. UN ENSAYO SOBRE EL PATRIMONIO CULTURAL DE LA HUMANIDAD
}

\author{
CARMEN ROMÁN SÁNCHEZ \\ Universidad de Sevilla \\ CARMEN CORTÉS ROMÁN \\ Universidad de Pablo de Olavide
}

\section{Resumen}

El obelisco que actualmente se encuentra en la Plaza de la Concordia de París, fue mandado erigir por Ramsés II y es el gemelo del que aún se encuentra frente a la fachada del templo de Luxor, en Egipto. El gobernador durante la primera mitad del siglo XIX, Mohammed Ali, lo ofreció a Francia por medio de Champollion. Pero ¿quién debería poseer el bien cultural en cuestión?. A lo largo de este ensayo intentaremos encontrar respuestas a ésta y otras cuestiones que nos surgen sobre este bien, su conservación y su titularidad, algunas de ellas complejas pues entran en juego diferentes perspectivas que no aúnan una única posible solución.

\section{Palabras clave}

Templo de Luxor, Obelisco, Patrimonio Cultural, Patrimonio Histórico, Patrimonio Natural, UNESCO, Pillaje, Ocupación, Devolución, Conservación.

\section{THE OBELISK OF RAMSES II IN FRANCE. AN ESSAY ABOUT THE CULTURAL HERITAGE OF HUMANIT}

\section{Abstract}

The obelisk that is currently located in the Place de la Concorde in Paris, was ordered to be erected by Ramses II and it is the twin of the one that is still in front of the facade of the temple of Luxor, in Egypt. The governor during the first half of the 19th century, Mohammed Ali, offered it to France through Champollion. But, who should own the cultural property in question? Throughout this essay we will try to find answers to this and other questions that arise about this good, its conservation and its ownership, some of them are complex due to different perspectives that come into play and do not combine a single possible solution.

\section{Keywords}

Luxor Temple, Obelisk, Cultural Heritage, Historical Heritage, Natural Heritage, UNESCO, Pillage, Occupation, Refund, Conservation

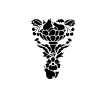




\section{Antecedentes: el obelisco de la concorde}

El obelisco de la Concorde (fig.1) tiene tres mil trescientos años de antigüedad, pesa 227 toneladas y mide casi 25 metros, sin incluir el pedestal. En 1830 el virrey otomano de Egipto, Mohammed Ali, lo ofreció a la monarquía francesa a través de Jean-François Champollion, famoso egiptólogo francés ${ }^{1}$; llegando a la capital parisina tras un dilatado viaje de tres años ${ }^{2}$. No es el más grande de su tipología, superado por ejemplo por el obelisco de Tutmosis III instalado en la plaza de San Giovanni de Roma, el de Hatshepsut situado en Karnak, o su propia pareja que permanece frente al pilono de entrada al Templo de Luxor ${ }^{3}$.

Razones como su crítico estado de conservación, contrastado a la mejor situación de su gemelo, o las voces que apelan el regreso a su lugar de origen -sin ningún éxito- nos plantean un interesante caso de conflicto entre Estados sobre la posesión de un concreto bien artístico de interés internacional; reflexión de las siguientes líneas.

\section{Patrimonio cultural de la humanidad de la Unesco}

Para entender las controversias y vicisitudes que surgen en torno al concepto de patrimonio se presenta imprescindible examinar brevemente el contexto normativo y filosófico del sistema internacional de protección, además de los diversos valores que adquieren mayor o menor relevancia en función de las varias definiciones de patrimonio cultural en el foro internacional. Bien sabido es que no existe una enunciación única y general de la noción de bien cultural a escala mundial y las que constan se restringen exclusivamente al marco legal concreto que las origina, recayendo su protección en la concreta actividad - declaración de un patrimonio de trascendencia mundial, protección en caso de conflicto armado, interdicción del comercio ilícito o amparo del patrimonio cultural subacuático o inmaterial- que se regula en la norma internacional. En otras palabras, el reconocimiento de ciertos valores afirmados y acogidos por comunidades internacionales también formulados por John Henry Merryman ${ }^{4}$ - que se encuentran ínsitos en el 'bien cultural' es lo que ciertamente origina la ausencia conceptual por parte de las Organizaciones Internacionales.

Tomando como ejemplo la Convención sobre las Medidas que Deben Adoptarse para Prohibir e Impedir la Importación, la Exportación y la Transferencia de Propiedad Ilícitas de Bienes Culturales de la United Nations Educational Scientific and Cultural Organization (UNESCO) del 14 de noviembre 1970, y más concretamente su artículo 1 en el que se proporciona un listado cerrado de hasta quince categorías de bienes culturales ${ }^{6}$, es posible

\footnotetext{
1 Champollion-Figeac, 1833. L'Hôte,1836.

2 Solé, 2007. Lebas/Fontana,1839.

3 Chabas, 1868: 4. Manniche, 1997. Michalowski/Frigola, 1991.

4 Merryman, 1986: 831-853.

5 Bator, 1982: 275-283.

${ }^{6}$ Según su tenor literal, art. 1 reza: «Para los efectos de la presente Convención se considerarán como bienes culturales los objetos que, por razones religiosas o profanas, hayan sido expresamente designados por cada Estado como de importancia para la arqueología, la prehistoria, la bistoria, la literatura, el arte o la ciencia y que pertenezcan a las categorias enumeradas a continuación: a) las colecciones y ejemplares raros de zoología, botánica, mineralogía, anatomia, y los objetos de interés paleontológico; b) los bienes relacionados con la bistoria, con inclusión de la historia de las ciencias y de las técnicas, la bistoria militar y la historia social, así como con la vida de los dirigentes, pensadores, sabios y artistas nacionales y con los acontecimientos de importancia nacional; c) el producto de las excavaciones (tanto autorizadas como clandestinas) o de los descubrimientos arqueológicos; d) los elementos procedentes de la desmembración de monumentos artísticos o bistóricos y de lugares de interés arqueológico; e) antigüedades que tengan más de 100 años, tales como inscripciones, monedas y sellos grabados; f) el material etnológico; g) los bienes de interés artístico tales como: i) cuadros, pinturas y dibujos hechos enteramente a mano sobre cualquier soporte y en cualquier material (con exclusión de los dibujos industriales y de los artículos manufacturados decorados a mano); ii) producciones originales de arte estatuario y de escultura en cualquier material; iii) grabados, estampas y litografías originales; iv) conjuntos y montajes artísticos originales en cualquier materia; b) manuscritos raros e incunables, libros, documentos y publicaciones antiguos de interés especial (bistórico, artístico, cientifico, literario, etc.) sueltos o en colecciones; i) sellos de correo, sellos fiscales y análogos, sueltos o en colecciones; j) archivos, incluidos los fonográficos, fotográficos y cinematográficos; k.) objetos de mobiliario que tengan más de 100 años e instrumentos de música antiguos».
} 
observar cómo se reconocen valores tales como el interés paleontológico, científico, histórico, arqueológico, artístico y monumental, literario y artístico, y etnológico para proporcionar una definición amplia a modo de clasificación que penderá de la expresa designación por cada Estado de la importancia de uno o varios de ellos ${ }^{7}$.

Otro convenio posterior de la UNESCO ha profundizado aún más en la noción de patrimonio universal y el valor internacional de carácter excepcional de cada uno de los bienes que lo conforman. En 1971 llega a la UNESCO un nuevo director de Patrimonio Cultural, Gérard Bolla, que comenzó identificando a los interlocutores que pudieran ayudar políticamente a esta nueva concepción. Los Estados Unidos respondieron con comentarios y sometieron la propuesta llamada World Heritage Trust Convention, que combinaba el objeto común de la preservación de cultura y naturaleza. El texto que se entregó por parte de la delegación de los Estados Unidos en 1972 define como objeto de la Convención a las zonas naturales y sitios culturales importantes para la historia de la civilización mundial, de gran valor antropológico, arqueológico, arquitectónico o histórico. El 16 de noviembre de 1972, la Organización de las Naciones Unidas para la Educación, la Ciencia y la Cultura adoptó, en el marco de su LXX Conferencia General celebrada en París, la Convención sobre la Protección del Patrimonio Mundial, Cultural y Natural, con el objetivo de proteger, a nivel internacional, los bienes culturales y naturales más significativos del planeta. Una valía universal se constituye a partir de una interacción entre distintas singularidades o puntos de vista de expertos y de miembros de Delegaciones Permanentes de los países que constituyen un nuevo órgano establecido por el tratado, el Comité de Patrimonio Mundial, asistido por organismos consultivos de carácter no gubernamental: el International Council on Monuments and Sites (ICOMOS) en los casos de bienes culturales y la International Union for Conservation of Nature (IUCN) en los relativos a los naturales. Análogamente, la dinámica por la cual un sitio es canonizado como parte del Patrimonio Universal, debe reflejar una conversación lo más plural posible, donde no se impongan visiones unidimensionales ni racionalidades reduccionistas, donde se representen las más diversas singularidades, y donde éstas puedan ser parte de un lenguaje común sin por ello consagrar saberes centrados. Eso sí, el origen de este proceso y la actuación del Comité es siempre a voluntad del Estado que propone la candidatura de un bien perteneciente a su patrimonio cultural nacional ${ }^{9}$, y que tras previo examen preceptivo de los informes emitidos por organismos consultivos, será incluido en la Lista del Patrimonio Mundial si se considera que reúne un valor universal excepcional junto con las condiciones de integridad, autenticidad y sistemas de protección nacional ${ }^{10}$. Esta Lista establece tres categorías de bienes - monumentos, conjuntos y lugares- que presentan un valor universal excepcional desde el punto de vista de la historia, arte y ciencia (para monumentos y conjuntos) y etnia o antropología (para lugares).

\footnotetext{
${ }^{7}$ Askerud/Clément, 1999.

8 Villaseñor/Zolla, 2012: 75-101.

9 Siguiendo lo establecido en el artículo 11.3 de la Convención «será preciso el consentimiento del Estado interesado para inscribir un bien en la Lista del patrimonio mundiab), por lo que se concluye que se parte de la premisa de que ese bien que pretende alcanzar valor universal, es ya parte del patrimonio nacional de dicho Estado.

${ }_{10}$ Véase al respecto las Directrices prácticas de aplicación de la Convención de 2013, en el parágrafo 77 , en el que se formulan hasta seis criterios para los bienes culturales: (i) representar una obra maestra del genio creador bumano; (ii) atestiguar un intercambio de valores humanos considerable, durante un periodo concreto o en un área cultural del mundo determinada, en los ámbitos de la arquitectura o la tecnología, las artes monumentales, la planificación urbana o la creación de paisajes; (iii) aportar un testimonio único, o al menos excepcional, sobre una tradición cultural o una civilización viva o desaparecida; (iv) ser un ejemplo eminentemente representativo de un tipo de construcción o de conjunto arquitectónico o tecnológico, o de paisaje que ilustre uno o varios periodos significativos de la historia humana; (v) ser un ejemplo destacado de formas tradicionales de asentamiento bumano o de utilización de la tierra o del mar, representativas de una cultura (o de varias culturas), o de interacción del hombre con el medio, sobre todo cuando este se ha vuelto vulnerable debido al impacto provocado por cambios irreversibles; (vi) estar directa o materialmente asociado con acontecimientos o tradiciones vivas, ideas, creencias u obras artisticas y literarias que tengan una importancia universal excepcional.
} 


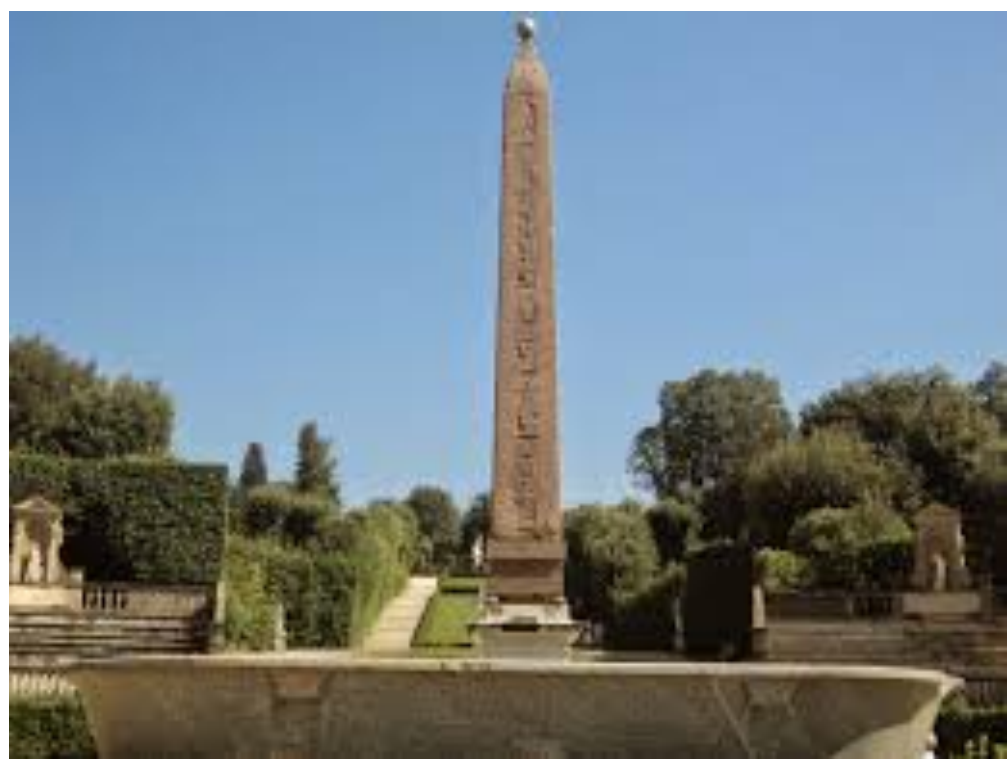

Fig.1. Obelisco de Ramsés II en París

El Templo de Luxor, junto con otros restos arquitectónicos, la Antigua Tebas y su necrópolis, capital del antiguo Imperio Egipcio, forman un conjunto histórico que pertenece al Patrimonio Cultural de la Humanidad desde el 26 de Octubre de 1979 (fig.2).

\section{¿A qué patrimonio cultural pertenece el obelisco?}

Este obelisco de origen egipcio que se encuentra desde 1833 en la ciudad francesa de París proviene del Templo de Luxor, y pertenece al Patrimonio cultural de la Humanidad, como así se recoge en la lista de la UNESCO desde el 26 de Octubre de 1979. Pero determinar si el obelisco de la Concordia forma parte de ese patrimonio mundial incluyéndose a su vez dentro del patrimonio nacional egipcio o del propio francés, no es tarea fácil.

El término 'patrimonio cultural' proviene de una fusión entre las nociones 'patrimonio histórico' y 'patrimonio natural', y ha ido adquiriendo a lo largo de la historia diferentes matices haciéndose más abierto, subjetivo y dinámico, aunque es posible resaltar algunos rasgos fundamentales. Primeramente, el patrimonio se relaciona con la cultura -no en todos sus aspectos- y con la naturaleza; está fuertemente unido al pasado de una sociedad pues es algo heredado ${ }^{11}$; y únicamente existe cuando posee una eficacia simbólica, esto es cuando se trata de una "porción de naturaleza o una producción material o intangible de una sociedad cuya significación y consideración social supera la cosa misma para convertirse en una representación de la sociedad que lo posee y lo ha heredado, y de su pasado: deviene de este modo en un signo de identidad cultural" ${ }^{12}$.

Si partimos del término expuesto anteriormente, distinguir a qué patrimonio pertenece podría ser muy complejo debido a que constituye una pieza de gran significación histórica para el pueblo egipcio, construido para glorificar la figura de Ramsés II -como delatan sus jeroglíficos y escrituras antiguas- considerándose como elemento conformador de la identidad de la población egipcia; pero al mismo tiempo, Francia recibió este monumento regalo intercambiado entre los países- pudiéndose entender como hecho de relevancia para el progreso de la civilización y de las relaciones internacionales entre Egipto y Francia. Con todo, es necesario considerar igualmente el concepto 'patrimonio de la humanidad'

\footnotetext{
${ }^{11}$ Capel Sáez, 2014.

12 Acosta, 2011: 103.
} 
introducido por la Convención de 1972, en el que se incluye el término anterior -histórico, cultural o natural- pero desde una proyección universal, con el objetivo de preservar y salvaguardar dicho patrimonio que tiene relevancia, no sólo para una identidad cultural concreta, sino para la humanidad (expuesto con mayor extensión ut supra) ${ }^{13}$. Al introducir esta nueva derivación de la noción patrimonio cultural, el obelisco no constituye únicamente un monumento que da significación a una identidad cultural singular sino que se extiende a toda la población mundial, por lo que a pesar de su origen en el patrimonio cultural egipcio y de su actual pertenencia al patrimonio francés, el obelisco de la Concordia concierne a toda la humanidad erigiéndose como World Heritage.

\section{¿Debe Francia devolver a Egipto el obelisco? ¿qué consecuencias podría tener la devolución por Francia del obelisco?}

Estas preguntas constituyen una cuestión clave en el debate sobre el patrimonio mundial: ¿quién debe poseer el bien cultural en cuestión?. La respuesta es altamente complicada pues entran en juego diferentes perspectivas que no aúnan una única posible solución. Tomando un punto de vista jurídico internacional, el bien ha sido adquirido de modo lícito intercambio- no habiendo razón objetiva para su devolución a su estado de origen, a no ser que el país francés así lo quiera. Esto se ve reflejado concretamente en la Convención de 1970 en su artículo cuarto ${ }^{14}$, en el que se recoge que los bienes culturales adquiridos mediante intercambios libremente consentidos o recibidos a título gratuito con el consentimiento de las autoridades competentes del país de origen de esos bienes, serán considerados bienes pertenecientes a dicho estado después de la transferencia. A pesar de que esta convención es de carácter irretroactivo, por lo que no sería posible aplicarla al caso en cuestión, se vislumbra la anterior ausencia de legislación sobre la materia y, con ello, el vacío legal con respecto a la propiedad de los bienes culturales. Efectivamente, al existir esa laguna jurídica y no haberse obtenido el bien de modo ilícito, se consideraría al obelisco como un bien de propiedad francesa y, por tanto, no existe deber jurídico de devolverlo.

Sin embargo, desde una mirada moral, cualquier monumento que se encuentre en un país diferente al de su origen debería ser devuelto, pues constituye un elemento de carácter histórico y cultural para el territorio original y porque además, para poder entenderlo, comprenderlo y admirarlo, es necesario advertir también su entorno social, geográfico, histórico, arquitectónico y cultural. El medio climático adquiere aquí gran importancia, ya que al modificar el hábitat del objeto en cuestión, y sobre todo si constituye una pieza de gran antigüedad, se altera su ecosistema, clima y microclima, lo cual puede perturbar gravemente su conservación, como sucede con el obelisco que se encuentra en la ciudad parisina, azotado por condiciones climáticas para las que ese material no estaba preparado.

13 Viene a colación el preámbulo de la Convención de la Unesco de 1972 para la protección del patrimonio mundial, cultural y natural, que reafirma no solo la pérdida cultural que supone para la misma nación, sino además, la gran repercusión y detrimento que deriva de este hecho para el patrimonio común de la humanidad: «un empobrecimiento nefasto del patrimonio de todos los pueblos del mundo».

${ }_{14}$ Artículo 4 de la Convención sobre las Medidas que Deben Adoptarse para Prohibir e Impedir la Importación, la Exportación y la Transferencia de Propiedad Ilícitas de Bienes Culturales de 1970: Los Estados Partes en la presente Convención reconocen que para los efectos de la misma, forman parte del patrimonio cultural de cada Estado los bienes que pertenezcan a las categorías enumeradas a continuación: a) bienes culturales debidos al genio individual o colectivo de nacionales de Estados de que se trate y bienes culturales importantes para ese mismo Estado y que hayan sido creados en su territorio por nacionales de otros países o por apátridas que residan en él; b) bienes culturales hallados en el territorio nacional; c) bienes culturales adquiridos por misiones arqueológicas, etnológicas o de ciencias naturales con el consentimiento de las autoridades competentes del país de origen de esos bienes; d) bienes culturales que hayan sido objeto de intercambios libremente consentidos; e) bienes culturales recibidos a titulo gratuito o adquiridos legalmente con el consentimiento de las autoridades competentes del país de origen de esos bienes. 


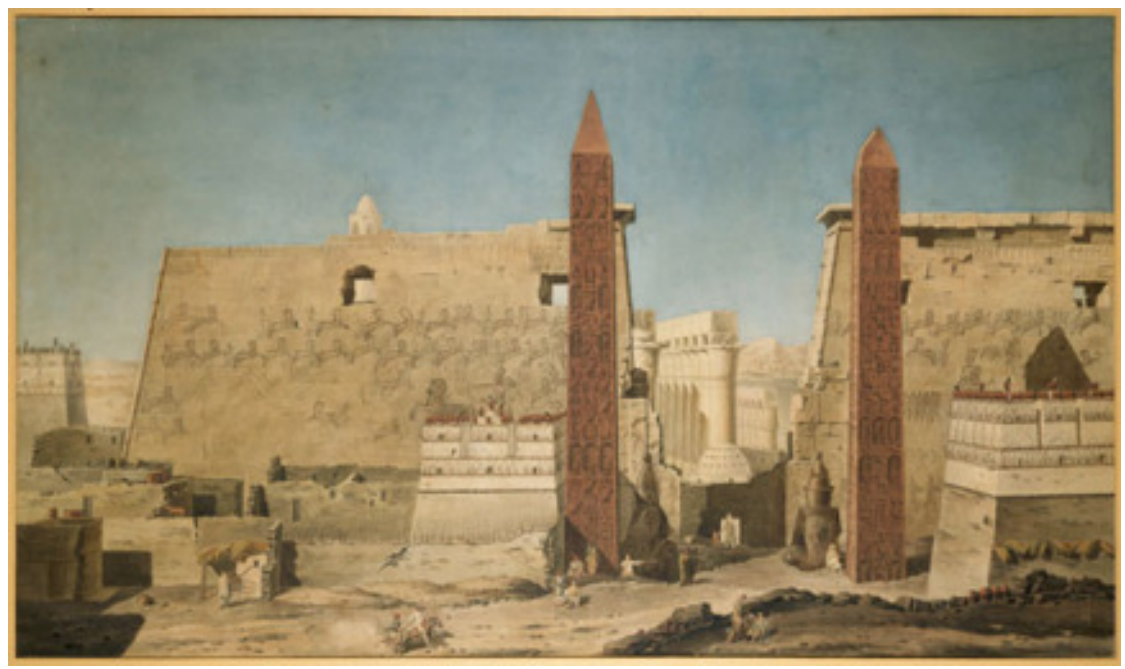

Fig .2. Pilono de entrada del Templo de Luxor. Acuarela de François-Charles Cécile, 1800. Musée du Louvre.

Muchos expertos ya advirtieron sobre el estado de conservación del monumento, como Eduard Porta -químico y conservador de museos, coordinador de la restauración de la tumba de Nefertari entre los años 1988 y 1992, y asesor del Museo Islámico de El Cairoque alertó de la amenaza de ruina del obelisco egipcio. Al estar construido en granito rosa de Asuán, era muy susceptible al clima templado y frío de París, con una precipitación media aproximada de $905 \mathrm{~mm}$ y una temperatura media anual de $7.5^{\circ} \mathrm{C}$. La gran piedra se estaba degradando por factores: térmicos, sales, contaminación atmosférica, biológicos y vibraciones provocadas por el tráfico de vehículos y el metro, produciendo largas y profundas grietas longitudinales, con pérdida de material. Sin embargo, el mecanismo de alteración que estaba y está dañando más la piedra es el aumento de volumen que se produce cuando el agua pasa de líquido a sólido; pues después de llover o nevar, si además hay un descenso de temperatura por debajo de $0^{\circ} \mathrm{C}$ el agua se congela y aumenta un $8 \%$ su volumen. Esa agua al helarse dentro de las grietas y poros del obelisco, actúa abriendo aún más las fisuras y poros de la piedra, lo que permite que entre más agua, y el ciclo continúe, abriendo camino a la acción de otros factores ${ }^{15}$, produciendo aumentos de porosidad del 40$50 \%$ en mármoles sometidos a ciclos con variaciones térmicas de $50^{\circ} \mathrm{C}^{\mathrm{p}}$. Por tanto, los factores térmicos están relacionados fundamentalmente con los indicadores de alteración de rupturas, disyunciones y deformaciones ${ }^{17}$. También cuando sale el sol, la piedra oscurecida por la suciedad y contaminación comienza a calentarse y lo hace rápidamente, pues al ser el granito un buen conductor, el agua se evapora, arrastrando y concentrando las sales solubles -algunas muy nocivas- como los sulfatos, actuando y deteriorando la piedra ${ }^{18}$. Así, el factor de degradación de las sales solubles produce principalmente en la roca depósitos y decohesiones importantes. Igualmente, hay factores biológicos como los microorganismos, que aportan materia orgánica necesaria para el asentamiento de otros organismos como hongos, líquenes y actinomicetos produciendo degradaciones como depósitos, moteados, desagregaciones, picados y fisuraciones ${ }^{19}$.

\footnotetext{
15 Antón, J. (2014): “Desfallece el obelisco del faraón”. En: < https://elpais.com/cultura/2014/03/17/actualidad/1395088044_371051.html> 10/09/2017.

${ }^{16}$ Rodríguez/Montoto, 1978: 2-7.

17 Ortega, 1982: 56-59.

18 García Gómez de Terreros/Alcalde, 2000.

19 Torraca,1982: 26. Alessandrini/Di Capitani, 1975: 137-167.
} 
Igualmente, la contaminación atmosférica provoca una degradación muy peligrosa, con el agravante de su imposibilidad de eliminación. Guidobaldi ${ }^{20}$, tiene una recopilación de los contaminantes atmosféricos en relación con sus efectos en los materiales pétreos, destacando: anhídrido sulfuroso (SO2), anhídrido carbónico (CO2), óxidos de nitrógeno (NOx), amoniaco (NH3) y los aerosoles de ácidos, sales, metales y partículas carbonosas, como factores muy degradantes. Sus efectos en el material están relacionados con otros factores, aunque destacan los depósitos y decohesiones. Por último, las vibraciones provocadas por el tráfico y metro pueden llegar a ser un factor determinante de riesgo para la piedra. Aunque en principio, la energía de la vibración puede parecer insignificante para afectar la consistencia mecánica de la roca, su acción continuada puede dar lugar a graves fenómenos de resonancia con un efecto visible: la apertura de las grietas, con la consecuente entrada de humedad al interior y los consiguientes efectos químicos y mecánicos ${ }^{21}$.

Para Porta no hay duda de que el obelisco estaría mejor en Luxor, ya que el daño sufrido ha sido mayor en los 180 años en París que en los más de 3.000 años que pasó en su sitio original. Además, basta con compararlo con su pareja para darse cuenta del deterioro; en Luxor, donde el clima es seco y la humedad muy baja, el promedio de las precipitaciones es de sólo 2 a $5 \mathrm{~mm}$ por año, el promedio de las temperaturas oscila entre $15^{\circ} \mathrm{C}$ en invierno y $50^{\circ} \mathrm{C}$ en el desierto durante los meses de verano y el aire es limpio ${ }^{22}$.

Pero ¿cuál sería la cuantía de una intervención integral de un monumento de gran interés histórico-artístico como el Obelisco de Ramsés II?. Un gran proyecto como este estaría dirigido por un importante centro internacional de conservación-restauración como el Centre National de Recherche Scientifique (CNRS); e intervendrían equipos interdisciplinares de ingenieros, arquitectos, arqueólogos, restauradores, historiadores, químicos, físicos y biólogos, entre otros. Se realizarían estudios previos como el levantamiento planimétrico, fotográfico, histórico, analítico; caracterización de materiales; identificación de los factores de alteración; evaluación de los productos de conservación y de restauración; técnicas instrumentales como la difracción de rayos $\mathrm{X}$, microscopio de barrido, espectroscopia con transformada de Fourier, cromatografía de gases, equipos de ultrasonidos, colorímetro, microclimático, ambiental, arqueológico, etc. Indudablemente sería un proyecto muy costoso, superando el millón de euros. $\mathrm{Y}$ al que habría que añadir un conjunto de intervenciones sobre el medio ambiente para minimizar o eliminar los factores contaminantes y de vibración en el terreno.

Las consecuencias de restituir un monumento como el Obelisco de la Concordia a Egipto son diversas. En primer lugar, el traslado del monolito a tierras egipcias facilitaría la conservación del mismo en un entorno climático propicio para ello, y se lograría reunir nuevamente el complejo arquitectónico del Templo de Luxor reafirmando su identidad histórica. Para Francia, esto podría implicar un detrimento en el turismo cultural de la capital francesa, aunque es complejo conocer a ciencia cierta dichas repercusiones. La realidad es que solo un número reducido de monumentos, museos y conjuntos patrimoniales que reciben cifras millonarias de visitantes se identifican como las joyas del mapa patrimonial mundial. Un ejemplo de ello es la Torre Eiffel, uno de los más visitados del mundo, por casi 7 millones de personas al año, de los cuales el $75 \%$ son extranjeros. Consultando las ofertas de los turoperadores para conocer París, la plaza de Concordia está en el número diez del top de lugares o monumentos imprescindibles ${ }^{23}$. Los turistas, sea por las fórmulas de presentar el patrimonio o por los intereses de los turoperadores, enfocan su atención sobre

\footnotetext{
${ }^{20}$ Guidobaldi/Mecchi/Segedin, 1998:14-48.

${ }^{21}$ García de Miguel/González/Sánchez/Puche, 1991: 23-33.

22 "Desfallece el obelisco del faraón". En: < www.iart.es/noticia/3813/desfallece-el-obelisco-del-faraon> $10 / 09 / 2017$.

23 Véase para mayor información sobre el turismo en París, Pearce, 1999: 24-46. Asimismo la web oficial francesa de la Torre Eiffel para consultar los datos oficiales sobre visitantes. En: $<$ https://www.toureiffel.paris/fr/le-monument/chiffres-cle $>28 / 09 / 2017$. Al respecto de las ofertas de los turoperadores, se puede consultar el siguiente artículo: "20 lugares que visitar en París imprescindibles". En: $<$ www.viajeroscallejeros.com/20-lugares-visitar-paris-imprescindibles/> 28/09/2017.
} 
un número reducido de monumentos, espacios y museos, aquellos que encarnan la identidad turística de los destinos, y que guardan relación con la imagen cultural y turística que se proyecta en las guías turísticas, etc. El turismo cultural es uno de los componentes con más proyección del sector turismo; ha pasado de ser un consumo elitista a un consumo de masas. Sería oportuno estudiar el efecto patrimonial en base a la oferta y demanda turística, que supondría el traslado del obelisco a su sitio original y su ausencia en la ciudad parisina, con toda la complejidad de aspectos que hay en la articulación entre patrimonio, turismo y desarrollo ${ }^{24}$. Al mismo tiempo, implicaría también una reducción de los gastos de restauración que antes se destinarían al obelisco y de la contribución a la recuperación funcional del patrimonio cultural ${ }^{25}$. Por último, no cabe duda que la realización de un acto como este supondría para Francia un refuerzo de las relaciones políticas con el país egipcio y viceversa, además de sentar precedentes jurídicos internacionales para posibles casos similares que puedan suceder en un futuro.

\section{¿Y si el obelisco hubiera sido obtenido por Francia como pillaje de guerra durante la campaña que napoleón llevó a cabo en Egipto?}

No hay lugar a dudas que "las guerras napoleónicas permitieron a los franceses apropiarse de una gran cantidad de obras de arte egipcias y, después, la expansión colonial de las potencias imperialistas dio lugar a que los museos metropolitanos de países como Inglaterra, Alemania o la propia Francia, se nutrieran con infinidad de piezas robadas durante todo el siglo XIX, con un afán de rapiña que lamentablemente no se detuvo en la centuria siguiente, 26 y, por esta razón, se comenzó a debatir en las esferas europeas, como en la Conferencia de Viena de 1815, sobre el principio de la restitutio in integrum de los países expoliados en Europa -como sucedía con Reino Unido, el cual defendía la restitución, al tiempo que su embajador británico Thomas Elgin traía en 1802 los mármoles del Partenón de Atenas que hoy día se encuentran en la colección del Museo Británico ${ }^{27}$-, aunque esto no constituyó como tal ningún precedente jurídico para la creación de una regla de restitución. Posteriormente, en 1954 se celebró en la Haya la IV sesión de la Conference Intergouvernementale sur la protection des Mens culturéis en cas de conflit armé de la UNESCO adoptándose la Resolución 6.42 sobre la defensa de los bienes de valor cultural, en la que se llevó a cabo la aprobación de la convención (Res.4.44) sobre la materia, primer paso hacia la cristalización de normas consuetudinarias de protección de bienes culturales en caso de conflicto armado ${ }^{28}$.

Por tanto, en este supuesto nos encontramos ante una situación diferente ya que conversamos sobre un contexto de guerra y expolio, lo cual implica una adquisición ilegal del bien cultural, si bien, la legislación sobre pillajes de guerra y restitución no estaba aún asentada en ese momento histórico y las posteriores convenciones no recogían carácter retroactivo. Por ello, la titularidad del bien sería relativamente dudosa al no existir obligación legal de restituir el bien -aunque sí el moral- a excepción de existir legitimación por parte de un órgano superior de la reclamación para la restitución del bien robado, debiendo ser devuelto a su país de origen.

\section{¿Y si el obelisco hubiera sido obtenido por Francia de las manos del reino unido, mientras este país ocupó colonialmente Egipto durante el siglo XIX?}

Aquí nos encontramos ante una situación muy similar a la anterior, con la discrepancia de que Reino Unido adquiriría el bien mediante un proceso de ocupación -ilícito-. Con respecto al régimen en caso de ocupación, se recoge una noción general de la idea de intervención mínima del país ocupante en el artículo quinto del Convenio de 1954: "una

\footnotetext{
24 Brandis, 2009: 72-99. Pérez, 2012: 58-72.

25 Troitiño Vinuesa/Troitiño Torralba, 2016: 13-15.

26 Peñalba, 2005: 177-206.

27 Williams, 1978: 7.

${ }^{28}$ Liesa, 2009: 243.
} 
potencia ocupante debe cooperar con las autoridades nacionales competentes en la salvaguardia y conservación de los bienes culturales". Aunque no es hasta el Protocolo de 1999 cuando se establecen límites a las exportaciones y desplazamientos de propiedad ilícitos de bienes culturales, excavaciones arqueológicas y transformación o modificación de la utilización de bienes culturales con las que se pretende ocultar o destruir testimonios de índole cultural, histórica o científica ${ }^{29}$. Sin embargo, nuevamente la legislación aplicable es un siglo posterior al momento de los hechos, por lo que en el supuesto que nos ocupa existiría un vacío legal, pudiendo considerar a Francia como poseedor del Obelisco, adquirido de mala fe a manos de Reino Unido, siempre que no exista una reclamación legitimada de Egipto para la restitución del obelisco.

\section{¿Podría intervenir alguna organización internacional obligando o recomendando a Francia la devolución?}

En un contexto en el que cada vez emergen más identidades patrimoniales estatales que responden a intereses sociales y económicos con el objetivo de obtener el control sobre determinados patrimonios culturales; hay algo que falla en la comunidad internacional. Con una legislación internacional muy débil en este campo y sin límites bien establecidos -soft law-; falta de precedentes en la materia; interés de las potencias por mantener los bienes bajo su posesión, etc. ${ }^{30}$; la necesidad de intervención por parte de una organización supranacional se hace evidente, al mismo tiempo que se alzan voces y grupos de presión reclamando la restitución de monumentos a sus lugares originarios como el Obelisco de Ramsés II o una de las Agujas de Cleopatra sita en Nueva York. Este último es un ejemplo interesante de requerimiento por parte del ministro de antigüedades egipcio, Zahi Hawass, al gobierno americano para garantizar su estado de conservación, amenazando con reclamar la devolución del mismo. Defensores del internacionalismo cultural sostienen, a colación de este asunto, que no hay mejor lugar para los bienes culturales que aquel donde se puedan conservar mejor $-\mathrm{y}$ en tanto que son patrimonio de la humanidad, ese lugar puede encontrarse en cualquier parte del territorio internacional- por lo que quizás ese obelisco no se encuentra en el sitio más oportuno para su conservación y debería ser trasladado. Sin embargo, es revelador que esta misma visión haya servido para justificar la negativa de la devolución a Grecia de los Mármoles del Partenón ${ }^{31}$, pues a pesar de ser más propicio el clima de origen, la fuerte contaminación en la Acrópolis valió de argumento en contra del traslado $^{32}$.

Empero, en todos estos casos de reclamaciones, además de la actuación de los Estados parte en la confrontación, está presente otro actor internacional, la UNESCO, que como bien se sabe, no fue creado para otra cosa más que para preservar y salvaguardar la herencia cultural mundial. En su mano está la creación de ágoras entre las naciones que favorezcan la conservación de bienes culturales y, si fuera preciso por este motivo o por razones morales o históricas, exigir la correspondiente devolución a su país de origen. No son meros enfrentamientos entre estados por la posesión de un bien nacional, sino bienes de la humanidad que requieren un ente superior que los supervise y un cuadro normativo internacional que salvaguarde su preservación por encima de cualquier interés nacional.

\footnotetext{
${ }^{29}$ Liesa, op. cit: $239-262$

30 Gerstenblith, 2000.

31 Merryman, 1985: 1881-1923.

32 Pérez-Prat Durbán, 2015: 127.
} 


\section{Bibliografía}

Acosta, E. Z.: "Sobre patrimonio y desarrollo. Aproximación al concepto de patrimonio cultural y su utilización en procesos de desarrollo territorial". En: Pasos: Revista de turismo y patrimonio cultural, 9, 1, (2011), pp. 101-113.

Alessandrini, G./Di Capitani, L.: "Investigations on the decay of Candoglia marble used in the Milan Duomo". En: The conservation of stone I. Proceedings of the international symposium, Centro per la conservazione delle sculture all'aperto, Bologna, (1975), pp. 137-167.

Askerud, P./Clément, E.: La prevención del tráfico ilícito de bienes culturales. Un manual de la UNESCO para la implementación de la convención de 1970. México. (1999).

Bator, P. M.: "An essay on the international trade in art". En: Stanford Law Review, 34, 2, (1982), pp. 275-384.

Brandis, D.: "La imagen cultural y turística de las Ciudades Españolas Patrimonio de la Humanidad" En: Ciudades Patrimonio de la Humanidad: Patrimonio, Turismo y Recuperación Urbana, Sevilla, (2008), pp. 70-97.

Capel Sáez, H.: El patrimonio: la construcción del pasado y del futuro. Barcelona: Ediciones del Serbal. (2014).

Chabas, F. J.: Traduction complète des inscriptions hiéroglyphiques de l'obélisque de Lonqsor Place de la Concorde à Paris. París: Maisonneuve. (1868).

Champollion-Figeac, J. J.: L'obélisque de Louqsor transporté à Paris: notice historique, descriptive et archaeologique sur ce monument: avec la figure de l'obélisque et l'interprétation de ses inscriptions hiéroglyphiques. París: Imprimerie de Firmin Didot Frères. (1833).

García Gómez De Terreros Guardiola, M./Alcalde Moreno, M.: Metodología de estudio de alteración y conservación de la piedra monumental. Sevilla: Secretariado de Publicaciones de la Universidad de Sevilla. (2000).

García De Miguel, J.M./González Aguado, M.T./Sánchez Castillo, L./Puche Riart, O.: "Impacto ambiental sobre el patrimonio monumental en piedra". En: Industria minera. $\mathrm{N}^{\mathrm{o}}$ 313, E.T.S. de Ingenieros de Minas de Madrid, (1991), pp. 23-33.

Gerstenblith, P.: "The Public Interest in the Restitution of Cultural Objects". En: Conn. J. Int'l L., 16. (2000).

Guidobaldi, F./Mecchi, A. M./Segedin, M.: "Acid rain and the corrosion of marble; The influence of the frequency of rainfall". En: VIth International Congress on deterioration and conservation of stone. Supplement. $=V$ Te Congrès International sur l'altération et la conservation de la pierre. Torun, Uniwersytet Mikolaja Kopernika w Toruniu., (1989), pp. 151-160.

Haxell, N. A.: "Hugo, Gautier and the Obelisk of Luxor (Place de la Concorde) During the Second Republic". En: Nineteenth-Century French Studies, 18, 1/2, (1989), pp. 65-77.

L'Hôte, N.. Notice historique sur les obélisques égyptiens et en particulier sur l'obélisque de Louqsor, rédigée d'après les meilleurs documens, et offrant les noms et époques des rois qui, ont fait ériger ces differens, monolithes par Nestor L'Hote, de l'expédition de Champollio le jeune, en Égypte et en Nubia. París: Éditeur du musée des antiquités égyptiennes. (1836).

Lebas, J. B. A./Fontana, D.: L'obelisque de Luxor. Histoire de sa translation. París: CarilianGœury et V. Dalmont. (1839).

Liesa, C. R. F.: "Evolución jurídica de la protección internacional de los bienes culturales en los conflictos armados". En: Anuario español de derecho internacional, 25, Navarra, (2009), pp. 239-262.

Manniche, L.: El arte egipcio. Madrid: Alianza Editorial. (1997).

Martinez, P.: "An unluckly success: voyage of the luxor obelisk to Paris". En: KMT, 18, 4, San Francisco, (2007), p. 65. 
Merryman, J. H.: “Thinking about the Elgin marbles". In: Michigan Law Review, 83, 8, (1985), pp. 1881-1923.

Merryman, J. H.: "Two Ways of Thinking about Cultural Property". En: American Journal of International Law, 80, 4, (1986), pp. 831-853.

Michalowski, K./Frigola, M. V.: El arte del antiguo Egipto. Akal. (1991).

Ortega, F.: Patología de la construcción. La obra de fábrica. Sevilla: Editan SA. (1982).

Pearce, D.: "Turismo en París. Estudios de microescala". En: Annals of Tourism Research en Español, 1,1, (1999), pp. 24-46.

Peñalba, J. L.: "Evolución del concepto y de la significación social del patrimonio cultural". En: Arte, individuo y sociedad, 17, Madrid, (2005), pp. 177-206.

Pérez, R. M.: "Turismo existencial y de masas en París-Tombuctú". En: Archivos de la Filmoteca, 69, (2012), pp. 58-72.

Pérez-Prat Durbán, L.: "La protección internacional del patrimonio y las comunidades patrimoniales". En: Anuario de la Facultad de Derecho de la Universidad Autónoma de Madrid, Madrid, (2015), pp. 121-151.

Rengifo Lozano, A.: "Avances y perspectivas del derecho para la restitución de bienes culturales a sus países de origen. El caso del patrimonio cultural". En: Prolegómenos. Derechos y Valores, 11, 22, Nueva Granada, (2008), pp. 119-140.

Solé, R.: El gran viaje del obelisco. De Luxor a París. Barcelona: Edhasa. (2007).

Torraca, G.: Porous building materials science for architectural conservation. Rome. (1982).

Troitiño Vinuesa, M. A./Troitiño Torralba, L.,: "Patrimonio y turismo: reflexión teórico conceptual y una propuesta metodológica integradora aplicada al municipio de Carmona (Sevilla, España)". En: Scripta Nova. Revista Electrónica de Geografia y Ciencias Sociales. XX, 543, Barcelona. (2016).

Villaseñor Alonso, I./Zolla Márquez, E.: "Del patrimonio cultural inmaterial o la patrimonialización de la cultura". En: Cultura y representaciones sociales, 6, 12, México, (2012), pp. 75-101.

Williams, S.A.: The International and nacional protection of movable cultural property. A comparative Study. New York: Oceana Publications. (1978). 